\title{
Effect of Range of Motion Exercise Program on Joints Function of Burned Lower Limbs Patients
}

\author{
Hanan Hamdi Ahmed 1 , Youssef Saleh Hassan ${ }^{2}$, Samia Youssef Sayed ${ }^{3} \&$ Rasha Ali Ahmed Abdelmowla $^{4}$ \\ 1. Nursing Specialist, Radiology Department, Assiut University Hospital \\ 2. Professor of Plastic Surgery, Faculty of Medicine, Assiut University, Egypt. \\ 3. Assistant Professor of Medical- Surgical Nursing, Faculty of Nursing, Assiut University, Egypt. \\ 4. Assistant Professor of Medical- Surgical Nursing, Faculty of Nursing, Assiut University, Egypt.
}

\begin{abstract}
:
Background: Range of motion exercise is a key component of burn therapy across all phases of care. Aim: Assess the effect of range of motion exercise program on joints function of burned lower limbs Patients. Research design: A quasi experimental (pre / post- test) research design was used. Setting: The study was conducted in burn unit at Al Shamla Hospital, Al Mabara Hospital and Al Eman Hospital. Sample: Purposive thirty adult patients (male and female) admitted to burn units. Tools: Patient's assessment sheet, joints function assessment (pre, post). Results; There was a statistical significance difference as regard patient range of motion on lower limb joints pre-post program implementation ( $\mathrm{p}<0.005$ ). Conclusion: lower limb joints function was improved among patients who received range of motion exercise program. Recommendation: Simple instructions hand book illustrating necessary information and range of motion exercise program should be available for lower limb burned patients and nurses working in burn unit.
\end{abstract}

\section{Keywords: Burned lower limbs, Joints function \& Range of motion exercise}

\section{Introduction}

Heat, chemicals, electricity, sunshine, or radiation can cause burns to the body's tissues. The most common causes of burns include scalding from hot liquids and steam, building fires, and flammable liquids and gases (Wohlsein et al., 2016).

Swelling, blistering, scarring, shock, and even death can all result from burns. It can also cause infections by destroying the skin's protective barrier. Burn treatment is determined by the cause of the burn, its depth, and the area of the body it affects (Gupta $\&$ Kumar, 2018) and (Cen et al., 2015).

The loss of motion of a joint or anatomic structure as a result of normal skin being replaced with extensible scar tissue is known as burn scar contracture. Burn scar contracture has been demonstrated to have a significant impact on a burn survivor's quality of life, especially in terms of physical function. Burn rehabilitation should include an emphasis on preventing or minimising contractures in the damaged area. If left untreated, burns can cause highly debilitating and deforming contractures, which can lead to substantial disability (Tan et al., 2019).

Exercise is generally considered to be a safe and efficacious approach to restoring physiological function in patients with various chronic diseases. However, inclusion of exercise regimens in the outpatient rehabilitation of patients who have undergone major trauma, such as a large burn, is not common, despite evidence demonstrating that exercise is an effective means of improving outcomes in this patient population (Schouten et al., 2019).

Burn rehabilitation is an important and crucial aspect of the recovery process. It's a procedure that begins on the first day of admission and lasts for months, if not years, following the initial occurrence. Burns rehabilitation should not be done by one or two people, but rather by a group of people, including the patient and, if suitable, their family (Chiwaridzo et al., 2016).

Burn rehabilitation attempts to reduce the negative effects of injury by maintaining range of motion, limiting contracture formation and scarring, maximizing functional capacity, maximizing psychological well-being, and increasing social integration. Elevation of the extremities to minimize swelling, pressure sore avoidance, anti-contracture positioning, splinting, stretching, range of motion exercises, and early mobilization are all part of acute rehabilitation (Rivas et al., 2018).

Range of motion programs are a care component of a burn therapist's responsibility to prevent contracture and promote wound healing. Pillows and drip stands (for elevation) can be employed as efficient placement solutions if they are easily available in the ward. Simple but constant posture from the start can significantly reduce the risk of contractures. Dorsal contracture at the ankle can be avoided by keeping the ankles at 90 degrees-use pillows to hold them in place and promote sitting with feet flat on the floor as long as there is no edema (Lee et al., 2016). 
Significance of the study:

Fire and heat resulted in 67 million injuries. This resulted in about 2.9 million hospitalizations and 176,000 deaths. Most deaths due to burns occur in the developing world (Vos et al., 2016). Incidence of burn cases in Egypt in (2020) were 250,000 cases about 190,000 of them died from low health care. From researcher's experience as a head nurse in burn unit at Al Oteify Hospital for 8 years, it was found that the burned patients can expose to scar contractures as a result of burn injury which impair the range of motion and function of the joints (Tan et al., 2019). From the researcher experience as a head nurse in burn unite, many burn contractures can be minimized or avoided completely by early intervention, so range of motion exercise program production a great role for improving function of joints and reduce or prevent contracture. So, the current study aiming to evaluate the effect of range of motion exercise program on joints function of burned lower limbs.

Aim of the study:

Assess the effect of range of motion exercise program on joints function of burned lower limbs patients.

\section{Hypothesis}

Lower limbs joints function will be improved in burned patients who are receive range of motion exercise program.

\section{Materials \& Methods:}

Research design: Quasi experimental (pre / posttest) research design was utilized to conduct this study.

Variable:

The independent variable in this study was the range of motion exercise program and the dependent variable was patient lower limbs joints function.

Setting: The study accompanied in burn unit at $\mathrm{Al}$ Shamla Hospital, Al Mabara Hospital and Al Eman Hospital.

\section{Sample:}

A purposive (30)thirty adult patients (male and female) were suitable to the study whose admitted to burn units at Al Shamla Hospital, Al Mabara Hospital and Al Eman Hospital. Their age ranged from 20 to 65 years.

Sample size:

A power calculation estimated that in order to detect an effect size of one group (pre / post- test) with a pvalue $<0.05$ and $80 \%$ power, confidence level 0.95 , so a sample size of (30) patients was needed.

\section{Study Tools:}

Two tools are used to conduct study:

Tool I: Patient's assessment: this tool consisted of two parts.
Part A: Demographic patient data:

It was developed to assess demographic characteristics. It was included age, sex, marital status, level of education and occupation.

Part B: Patient medical data:

It was developed to assess past and present medical history. It included cause of burn, degree of burn, percent of burn, first aid, skin graft, joint affected, date of admission and date of discharge.

Tool (II): Joints Function Assessment (pre, post): by using severity rating contracture scale which was developed by (Schneider et al., 2006). This scale divide contracture into three levels (mild, moderate and severe). This tool was applied by the researcher by using a goniometer with a standardized technique (Norkin and White, 1958).

This tool was assessed four times (pre-program when the patient admitted in the burn unit, immediately post program, 2 weeks and 6 weeks post program).

\section{Scoring system:}

According to the severity rating contracture scale the degree of contracture will be specified into three levels, mild, moderate and severe contracture (as the following table).

Severity Rating Contracture Scale:

\begin{tabular}{|c|l|c|c|c|c|}
\hline $\begin{array}{c}\text { Lower } \\
\text { Limp } \\
\text { Joint }\end{array}$ & Muscle Action & Mild & Moderate & Severe & Expected \\
& & & & & \\
\hline \multirow{3}{*}{ Hip } & Flexion & $\mathbf{6 7}$ to 100 & $\mathbf{3 4}$ to 66 & $<34$ & 100 \\
& Extension & $\mathbf{2 0}$ to 30 & 10 to 19 & $<10$ & 30 \\
& Abduction & $\mathbf{2 6}$ to 40 & 13 to 25 & $<13$ & 40 \\
& Adduction & 13 to 20 & 7 to 12 & $<7$ & 20 \\
\hline knee & Flexion & 100 to 150 & $\mathbf{5 0}$ to 99 & $<50$ & 150 \\
& Extension & -150 to 100 & -99 to 50 & $<-50$ & 0 \\
\hline \multirow{2}{*}{ Ankle } & Dorsiflexion & 13 to 19 & 6 to 12 & $<6$ & 20 \\
& Plantar flexion & 26 to 39 & 13 to 25 & $<13$ & 40 \\
& Inversion & 20 to 29 & 10 to 19 & $<10$ & 30 \\
\hline
\end{tabular}

Tools validity and reliability:

- Face validity was done by (5) experts from Medical-Surgical Nursing staff and Medical staff who reviewed the tools for clarity, relevance and comprehensiveness.

- Minor changes were done and correction was carried out accordingly and then the tools were designed in their final format and tested for reliability.

- Reliability of the tool was measured by Cronbach's alpha coefficient ( $\mathrm{r}=0.72$ ).

Range of motion exercise program:

It was developed by the researcher based on national and international literatures review. It was prepared in the formula of booklet written in simplified Arabic language and supported by photo illustration and colored pictures to be suitable for all patients regardless to their educational level.

It was designed to maintain and improves joint function of burned patients. This Range of motion 
exercises help to keep the muscles and joints of the burned limbs flexible.

it included:

Part (1): anatomy and function of the skin, definition, causes and degrees of burn and its' complication on the joints.

Part (2): Rang of motion excesses; its types, benefits, when, how to perform.

Part (3): positions that patients should follow to prevent contracture occurrence. Its types its benefits.

-Burn patients have a high developing contractures and proper positioning attempts to prevent this complication.

-Anti- contracture positioning may assist in the reduction of edema. This session took about 15 minutes.

Part (4): splints: types how to use when to use its benefits.

Procedure:

This study was conducted through three phases:

Phase (I): Preparatory phase:

- An official permission to conduct this study was obtained from the head of burn unit at three hospitals.

- Tools development

- Through reviewing the current, past, local and international related literature in the various aspects using articles, books, periodicals, magazines and references were done.

Ethical Considerations:

- Research proposal approved from Ethical Committee in the Faculty of Nursing by ethical code No. (2330011).

- The study was following common ethical principles in clinical research.

- After explaining the nature and purpose of the study, an oral consent was obtained from patient or guidance that is willing to participate in the study.

- No risk for study subject during application of the research.

- Confidentiality of the subject data was assured.

- The researcher informed that participation that voluntary withdraw at any time of the study.

- Anonymity measured during collection of data.

Pilot study:

- A pilot study on (10\%) (3) Patients were accompanied during August, 2020 in order to test the clarity and applicability of the tools. According to this pilot study, the required modifications were made.

- Those patients who were involved in the pilot study were included in the study.

Phase (II): Implementation phase:

- Once the permission was granted to proceed with the proposed study, the researcher initiated data collection, name of potential patients who have admitted to the unit and who met the criteria were obtained from the medical sheet of the patient.

- This phase included four sessions:

- First session, started during 24 hours post admission after fluid resuscitation and wound dressing.

- The researcher greeted the patients, introduced herself to patients who agreed to participate in the study prior to any data collection.

- Each patient involved in the study was interviewed individually for filling (Tool I).

- The researcher assessed lower limbs joints function by using (Tool II), this part applied by using the goniometer.

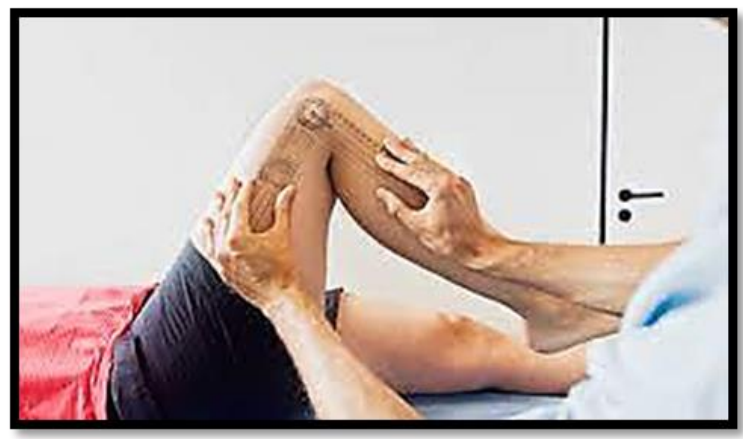

Fig: Goniometer, adopted from karmer, 2019

- The researcher explained range of motion exercise program for patient and one family member was present in the session for patient's support and increasing their sense of responsibility.

- Range of motion exercise program includes the following items: anatomy and function of the skin, definition, causes and degree of burn and complications of burn on joint.

- The session took about 10-15 minutes.

- Second session; the researcher explained in details the suitable range of motion exercise program and how to apply. The important of positioning was explained. Importance of anti-contracture positioning in reducing edema.

- Third session: If the patient has no skin grafting, range of motion activities can be started promptly after 24 hours, and usually 1 week following grafting to avoid interfering with the graft take.

- Cross-joint burns and burns resulting in exposed tendons require special treatment.

- These joints are at a high risk of contracture and should be splinted empirically and treated with ROM.

- Repeat each exercise 10 times, 3 times a day.

- Exercise could begin with passive, activeassistant, and active range of motion training on main joints (with or without burn injury).. 
- -Range of motion exercise can be very painful at the beginning so, mild analgesics are helpful initially to help the patient move and ambulate.

- At the beginning, the most optimal time to do ROM is during dressing changes when the patient is medicated and the bulky dressings are removed and then increase gradually through the day.

- If you have unsteady vital signs (high temperature) or a life-threatening condition, you should modify your exercise routine (presence of bleeding).

- Positioning during exercise is designed based on individual patient needs and medical status dictates.

- Fourth session: Splinting is important to maintain the burned part in the correct position as a complete work for ROM exercises and positioning to offset the counteracting of the wound.

- Splinting maintains anti-contracture positioning, which is very important for patients who are in a lot of pain, and gives a stretched position, which is also a better starting place for exercise.

- After completing the session there were about 1020 minutes for explaining and feedback. To ensure that the patient understood, reinforcement was done according to their needs.
- Each patient received a hard copy of the booklet, and the researcher employed illustrations to aid patient comprehension and retention of the information taught.

- The collection of data lasted through the period from August 2020 to January 2021.

Phase (II): Evaluation phase:

The researcher assessed lower limbs joints function three times using (Tool II) immediately post program after 2 and 6 weeks from patient admission.

\section{Statistical analysis}

The researcher entered the data using a suitable personal computer. For analysis, all data was entered into the statistical packages for the social sciences (SPSS) version 22.0 software, and figures were created in Excel. The researcher evaluated, categorized, and coded the material of each tool. Categorical variables were described by number and percent, where continuous variables described by mean and standard deviation (Mean, SD). Chi-square test and fisher exact test used to compare between categorical variables where compare between continuous variables by t-test and ANOVA test. A two tailed $\mathrm{p}<0.05$ was considered statistically significant.

\section{Results:}

Table (1): Distribution of studied patients as regarding to their demographic characteristics $($ no $=$ 30)

\begin{tabular}{|c|c|c|c|}
\hline \multicolumn{2}{|c|}{ Demographic data } & $\mathbf{N}=\mathbf{3 0}$ & $\%$ \\
\hline \multirow{5}{*}{$\begin{array}{l}\text { Age groups } \\
\text { (Years) }\end{array}$} & $20<25$ & 11 & 36.7 \\
\hline & $25<35$ & 3 & 10 \\
\hline & $35<45$ & 15 & 50 \\
\hline & $45<55$ & 0 & 0 \\
\hline & 55 -less than 65 & 1 & 3.3 \\
\hline \multicolumn{2}{|l|}{ Mean \pm SD } & \multicolumn{2}{|c|}{$32.5 \pm 8.7$} \\
\hline \multirow{2}{*}{ Sex } & Male & 22 & 73.3 \\
\hline & Female & 8 & 26.7 \\
\hline \multirow{2}{*}{ Marital status } & Single & 11 & 36.7 \\
\hline & Married & 19 & 63.3 \\
\hline \multirow{3}{*}{ Level of education } & Illiterate & 1 & 3.3 \\
\hline & Second & 10 & 33.3 \\
\hline & University & 19 & 63.3 \\
\hline \multirow{4}{*}{ Occupation } & Manual work & 9 & 30.0 \\
\hline & Machinery & 1 & 3.3 \\
\hline & Housewife & 9 & 30.0 \\
\hline & Non employment & 11 & 36.7 \\
\hline
\end{tabular}


Table (2): Frequency distribution of studied patients regarding the medical data (No. =30)

\begin{tabular}{|l|l|c|c|}
\hline \multirow{2}{*}{ Medical data } & N.=30 & \% \\
\hline \multirow{2}{*}{ Chronic illness } & No chronic disease & 29 & 96.7 \\
\cline { 2 - 4 } & Hypertension & 1 & 3.3 \\
\hline \multirow{2}{*}{ Degree } & Scaled & 10 & 33.3 \\
\cline { 2 - 4 } & Flam & 20 & 66.7 \\
\hline \multirow{2}{*}{ First aids } & Mixed $\left(1^{\text {st }}, 2^{\text {nd }}\right.$ and $\left.3^{\text {rd }}\right)$ & 30 & 100.0 \\
\hline \multirow{2}{*}{ Skin graft } & Yes & 20 & 66.7 \\
\cline { 2 - 4 } & No & 10 & 33.3 \\
\hline length of hospital stay (days) & Yes & 1 & 3.3 \\
\cline { 2 - 4 } & No & 29 & 96.7 \\
\hline
\end{tabular}

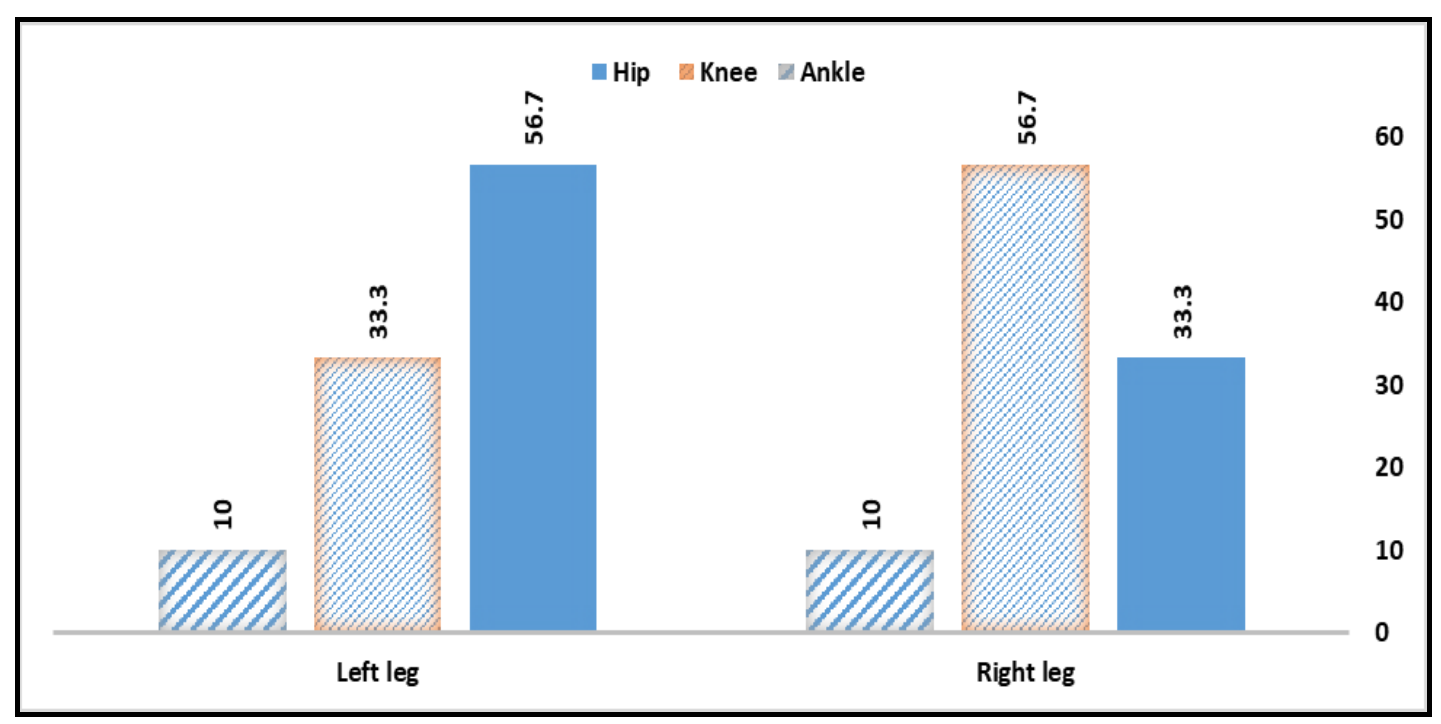

Fig (1): Frequency distribution of studied patients regarding joints affected with burn (No. $=30$ )

Table (3): Distribution of patients as regarding to assessment of lower limbs joint function of pre, immediately, post program ( 2 and 6 weeks) after implementation of range of motion exercise program (no.=30)

\begin{tabular}{|l|c|c|c|c|c|}
\hline \multicolumn{1}{|c|}{ Join } & $\begin{array}{c}\text { Pre program } \\
\text { (on admission) }\end{array}$ & $\begin{array}{c}\text { Immediately } \\
\text { post program }\end{array}$ & $\begin{array}{c}\text { Post program } \\
\text { (2 weeks) }\end{array}$ & $\begin{array}{c}\text { Post program } \\
\text { (6 weeks) }\end{array}$ & P. value \\
\hline Hip & & & & & \\
\hline Flexion & $156.34 \pm 7.21$ & $149.44 \pm 7.21$ & $176.76 \pm 5.21$ & $178.75 \pm 4.21$ & $0.001^{*}$ \\
\hline Extension & $46.16 \pm 3.1$ & $45.16 \pm 4.1$ & $47.16 \pm 0.1$ & $49.16 \pm 0.1$ & $0.034^{*}$ \\
\hline Abduction & $154.64 \pm 6.21$ & $144.34 \pm 5.42$ & $156.55 \pm 6.56$ & $158.64 \pm 6.27$ & $0.006^{*}$ \\
\hline Adduction & $50.0 \pm 0$ & $50.0 \pm 0$ & $50.0 \pm 0$ & $50.0 \pm 0$ & -- \\
\hline Knee & & & & & \\
\hline Flexion & $138.44 \pm 7.21$ & $132.76 \pm 1.21$ & $139.55 \pm 2.21$ & $140.55 \pm 2.21$ & $0.031^{*}$ \\
\hline Extension & $30.16 \pm 0.1$ & $30.66 \pm 6.1$ & $39.76 \pm 7.1$ & $40.86 \pm 1.1$ & $0.061^{*}$ \\
\hline Pronation & $80 \pm 0$ & $80 \pm 0$ & $80 \pm 0$ & $80 \pm 0$ & -- \\
\hline Supination & $76 \pm 0.98$ & $77 \pm 0.67$ & $77 \pm 0.88$ & $80 \pm 0$ & $0.044^{*}$ \\
\hline Ankle & & & & & \\
\hline Flexion & $54.77 \pm 6.7$ & $56.6 \pm 4.5$ & $59.88 \pm 4.9$ & $59.99 \pm 2.5$ & $0.019^{*}$ \\
\hline Extension & $51.97 \pm 4.8$ & $52.16 \pm 8.5$ & $52.87 \pm 7.9$ & $52.89 \pm 9.5$ & 0.798 \\
\hline Inversion & $29 \pm 0.8$ & $29.7 \pm 0.3$ & $30 \pm 0.0$ & $30 \pm 0.0$ & $0.012^{*}$ \\
\hline Eversion & $19 \pm 0.8$ & $19.0 \pm 0.3$ & $19.6 \pm 0.4$ & $20 \pm 0.0$ & 0.381 \\
\hline
\end{tabular}


Table (1): Illustrates that the mean age of patient was $(32.5 \pm 8.7)$ years old. The highest percentage of studied patients was males, married and university education 22, 19, 19 (73.3\%, 63.3\%, 63,3\% respectively). Regarding occupation it was found that the highest percentage was non employment 11 (36.7\%).

Fig (1): Shows that the highest percentage of studied patients had knee burn $17(56.7 \%)$ of the right leg, and hip burn $17(56.7 \%)$ of the left leg respectively.

Table (2): Shows that the majority 29 (96.7\% ) of the studied patients had no chronic diseases, the main cause of their burn was flam followed by scald 30 $(66.3 \%), 10(33.3 \%)$ respectively and all $30(100 \%)$ of the studied patients was represented by mixed degree burn $\left(1^{\text {st }}\right.$ and $\left.2^{\text {nd }}\right)$. The mean hospital stay of the studied patients was $(21.5 \pm 8.39$ days $)$

Table (3): Illustrates that there was a statistical significant difference as regarding patient joint function in different lower limb joints between pre, immediately, 2 and 6 weeks after implementation of range of motion exercise program.

\section{Discussion:}

The loss of motion of a joint or anatomic structure as a result of normal skin being replaced with extensible scar tissue is known as burn scar contracture. Burn scar contracture has been demonstrated to have a significant impact on a burn survivor's quality of life, especially in terms of physical function. Contractures should be avoided or minimised as part of burn therapy (Serghiou et al., 2018). Positioning programs are a care component of a burn therapist's responsibility to prevent contracture and promote wound healing (Godleski \& Umraw, 2020).

So, this study aimed to evaluate the effect of range of motion exercise program on joints function of burned lower limbs.

Regarding the demographic data of studied patient, the exciting study illustrated that the mean age of patient was age of manhood and maturity. Study of Ramirez-Blanco et al., (2017) founded that the majority of burned patients were ranged from twenty to forty years old.

The highest percentage of studied patients was male, married and university education. This agreed with study of Ahmed et al., (2020) who found that married female victims far outnumbered unmarried females, their ratio being married patients near to double single. This result was incompatible with Choudhary et al., (2019) who mention that burn injuries were reported to be more common in the lower socioeconomic strata and among those of working age. Regarding occupation it was found that the highest percentage was non employment. This match with Bailey et al., (2019) who found that the reason for the young burned patients suffering from burn because they are more active at their homes.

A study of Lee et al., (2016) who entitled "A single institution retrospective review of incidence, etiology, and outcomes" found that the major number of burned patients were males.

Females begin cooking at a young age, making them more susceptible to fire-related injuries. Similarly, kerosene stoves are more often used than liquefied petroleum gas burners. puts the kitchen's security at risk (Bailey et al., 2019).

The researcher opinion that female who deal with cooker that most cause of injury in addition to the lack of protection and first aid awareness toward burn injuries.

Regarding the medical data:

The current study showed that the majority of the studied patients, the main cause of their burn was flam followed by scald and all of the studied patients were presented by mixed degree burn. This was not in the same line with Assadian et al., (2015) who mentioned that scald is the most common cause of burn injuries in both men and women. Scalds account for approximately a third of the overall number of people accepted.

Few studies have found that individuals who suffer thermal burns have a greater mortality rate than those who suffer scald injuries. Higher TBSA involvement, greater depth of burns, and related inhalational injury all contribute to higher mortality in thermal burn patients Zhou et al., (2019).

The current study found that the mean hospital stay of the studied patients was less than one month. This matched with Furtado et al., (2020) who founded that the mean hospital length of stay of the burn injury was twenty-five days. A study of Mason et al., (2017) mentioned that the mean burned patients' hospital admission was thirty-five days.

The researcher opinion that the differences between patients length of hospital stay are related to such factors; age, health status causes and degree of burn and process of wound healing.

The current study showed that the majority of the studied patients had no chronic diseases. This same to the study of Barrett et al., (2019) who found majority of the studied burned patients free from any chronic diseases. But this not match with Zhou et al., (2019) who found that the majority of the burn patients suffered from diabetes mellitus.

This study revealed that majority of the studied patients had a mixed burn degree. This disagreed with study of Frew et al., (2019)who founded that more than half of the burns were presented with second degree burn.

Regarding joints affected with burn and effects of the range of motion exercises program: 
The present study showed that the highest percentage of studied patients had knee burn of the right leg, and hip burn of the lift leg. This match with study of Luca-Pozner et al., (2020) who founded that the most lower limb burn was the knee joint of the right leg. In the other hand Douglas et al., (2019) founded no statistical significance difference found amongst the right and left legs regarding the most site of burn. The researcher opinion was that the gravity play a great role in fluid burns specially the lower limbs that considers the first site face this hot objects or fluids to contact. This opinion is match with Aguilera-Saez et al., (2020) who founded that the lower limb is the most site of burn after trunk.

From the researchers point of view, the improvement of joint's flexibility occurred related to starting and applying ROM exercises early, in the emergency phase of burn before the healing process beginning. After healing, the contractures occurred and the movement become difficult and painful.

The present study illustrated that there was a moderate improvement in the patient joint function in different lower limb joints between pre and immediately application of the range of motion program. Post program (two weeks) after implementation of range of motion exercise program there was mild improvement and post program (six weeks) after implementation of range of motion exercise program there was not affected joints with contracture regarding knee and ankle joint. There was a statistical significant difference as regarding patient joint function in different lower limb joints in immediate and post program (two and six weeks) after implementation of range of motion exercise program.

After burn, the knee joint loses flexibility, and the muscles around the joints and in the muscles tend to atrophy, so rehabilitation is required in order to strengthen the surrounding muscles and stabilize the joint. All treatment options require extensive physical therapy to regain muscle strength and flexibility around the knee and restore ROM (Villafañe et al., 2019). In this regard, Eid et al., (2020) founded that subjects demonstrate significant improvements in ROM and balance from admission to discharge. This match with study of $\mathbf{V u}, \boldsymbol{\&}$ Kowalske, (2020) who reported that range of motion and splinting are used to enhance healing process.

Goniometric measurement of the joint ROM, remain the most versatile and widely used method. It is objective, reliable and valid method for measuring ROM, for the most application to extremities. The universal goniometer is still the preferable instrument for measuring ROM effect (Keogh et al., 2019).

The greater improvements can be attributed to the combined effects of both ROM and the traditional physical therapy program. These results were hand in hand with the study introduced by Özkal et al., (2020)who found that there was a significant improvements in walking characteristics and goniometric data were attributed to the immobilization of muscles in a lengthened, position and the increased muscles length.

A study of, Eid et al., (2020) illustrated that burn injuries cause substantial physical and psychological difficulties, necessitating a thorough and interdisciplinary rehabilitation program aimed to minimizing long-term scarring, contractures, and other physical function limiting issues.

In this regard, Bai et al., (2020) reviewed that there is evidence that rehabilitative exercise training can help burn survivors regain physiological function.. In addition, Özkal et al., (2020) mentioned that exercise rehabilitation aids in the maintenance and development of muscle strength, joint function, deformity prevention, circulation stimulation, endurance development, and relaxation. After an injury or surgery, rehabilitation has long been thought to be one of the most important components in restoring muscle strength and neuromuscular control and returning to regular activities and sports. The main functional impairments in burn victims are muscle weakness and decreased neuromuscular control of the lower extremity (Joo et al., 2020).

In the opposite side Eid et al., (2020) founded that the presence of complications can't be affected by the physiotherapy treatment but the surgery early excision mainly make changes and control the complications mainly contracture, however massage or ROM decrease itching and pain but not contracture.

The goal of burn rehabilitation is to reduce the negative effects of the injury by maintaining range of motion, reducing contracture development and scarring, and reducing functional handicap (Chelidze et al., 2016). Post burn contractures are perhaps the most dreaded and distressing morbidity in patients surviving major burns. Rapid and immediate rehabilitation make it easy for the patients to return to function early (Burns et al., 2017).

Regarding the correlation co-efficient between lower limbs joint function and the studied patients' age, TBSA and the length of hospital stay, the present study showed that there was a statistically significance difference between TBSA and both (hip post program after 6 weeks knee flexion ,immediately, post program (two and six weeks) and ankle flexion after post program (two and six weeks) of range of motion exercise program and ankle extension immediately post range of motion exercise program. 
Few studies have found that individuals who suffer thermal burns have a greater mortality rate than those who suffer scald injuries. Higher TBSA involvement, greater depth of burns, and related inhalational injury all contribute to higher mortality in thermal burn patients (Abenorku et al., 2013).

This match with study of Furtado et al., (2020) who founded a great correlation between the injury burn healing with the patients' ages. A study of Wagner and Clevenger, (2010) added that the greater the TBSA the greater the incidence of joint complication (contracture) delayed healing.

These findings were consistent with Snowdon et al., (2018) who founded all patients, linear measures of functional status showed significant gains from admission to discharge. Furthermore, all patients showed considerable functional improvements, indicating that inpatient rehabilitation can be considered an important part of burn therapy.

Finally, starting ROM exercises of burn patient early, from the first day of admission increase and improves the joints' flexibility, muscles strength and prevent muscle contracture that lead to loss of function.

\section{Conclusion:}

The study findings supported the research hypothesis as it had been proven that there an improvement on the function of joint on the six weeks from admission; in spite of decline on mean range of motion at three weeks (normal component of the healing process). Joint function was improved among patients who received range of motion exercise program.

\section{Recommendation:}

Simple instructions hand book illustrating necessary information and range of motion exercise program should be available for lower limb burned patients and nurses working in burn unit.

\section{References:}

- Abenorku P., Agbenorku M. \& Fiifi-Yankson P.K. (2013): Pediatric burns mortality risk factors in a developing country's tertiary burns intensive care unit. International journal of burns and trauma Trauma; 3(3):151-8.

- Aguilera-Saez, J., Lopez-Masramon, B., Collado, J., Monte-Soldado, A., Rivas-Nicolls, D., Serracanta, J., \& Barret, J. (2020): Severely damaged lower limb salvage in a critically ill burned patient. Lessons learned. International Journal of Burns and Trauma, 10(5), 191.

- Ahmed, N., Magbool, F., Hassan, Y., \& Khalil, S. (2020): Relation Between Incidence and Risk Factors of Septicemia Among Burned Patients (A Suggested Nursing Educational Brochure). Assiut Scientific Nursing Journal, 8(21), 196-205.
- Assadian, O., Arnoldo, B., Purdue, G., Burris, A., Skrinjar, E., Duschek, N., \& Leaper, D. (2015): A prospective, randomised study of a novel transforming methacrylate dressing compared with a silver-containing sodium carboxy methylcellulose dressing on partial-thickness skin graft donor sites in burn patients. International wound journal; 12(3), 351356.

- Bai, Z., Fong, K., Zhang, J., Chan, J., \& Ting, K. (2020): Immediate and long-term effects of BCI-based rehabilitation of the upper extremity after stroke: a systematic review and metaanalysis. Journal of neuro-engineering and rehabilitation, 17, 1-20.

- Bailey, M., Sagiraju, H., Mashreky, S., \& Alamgir, H. (2019): Epidemiology and outcomes of burn injuries at a tertiary burn care center in Bangladesh. Burns, 45(4), 957-963.

- Barrett, L., Fear, V., Waithman, J., Wood, F., \& Fear, M., (2019): Understanding acute burn injury as a chronic disease. Burns \& trauma, 7(1), 78-99.

- Burns, A., Marino, R., Kalsi-Ryan, S., Middleton, J., Tetreault, L., Dettori, J., \& Fehlings, M., (2017): Type and timing of rehabilitation following acute and subacute spinal cord injury: a systematic review. Global spine journal, 7 (3_suppl), 175S-194S.

- Cen, Y., Chai, J., Chen, H., Chen, J., Guo, G., Han, C. \& Li-Tsang, C., (2015): Guidelines for burn rehabilitation in China. Burns \& trauma, 3(1), 20.

- Chelidze K, Lim C, Peck R, Giiti G, Leahy N, \& Rabbitts A. (2016): Predictors of mortality among pediatric burn patients in East Africa. J Burn Care Res; 37(2):154-60.

- Chiwaridzo, M., Zinyando, V., Dambi, J., Kaseke, F., Munambah, N., \& Mudawarima, T. (2016): Perspectives of caregivers towards physiotherapy treatment for children with burns in Harare, Zimbabwe: A cross-sectional study. Burns \& trauma, 4(1), 31.

- Choudhary, V., Kumar, P., Kumar, P., Kumar, P., \& Kumar, S. (2019): Epidemiological study of burn admissions in a tertiary burn care center of Bihar, India. Indian Journal of Burns, 27(1), 63.

- Douglas, H., Lynch, J., Harms, K., Krop, T., Kunath, L., van Vreeswijk, C., \& Rea, S. (2019): Carbon dioxide laser treatment in burnrelated scarring: A prospective randomised controlled trial. Journal of Plastic, Reconstructive \& Aesthetic Surgery, 72(6), 863-870.

- Eid, M., Abdel basset, W., Abdel aty, F., \& Ali, Z., (2020): Effect of physical therapy rehabilitation program combined with music on 
children with lower limb burns: A twelve-week randomized controlled study. Burns, 451.

- Frew, Q., Rennekampff, H., Dziewulski, P., Moiemen, N., Zahn, T., \& Hartmann, B., (2019): Betulin wound gel accelerated healing of superficial partial thickness burns: Results of a randomized, intra-individually controlled, phase III trial with 12-months follow-up. Burns, 45(4), 876-890.

- Furtado, R., Berwanger, O., Fonseca, H., Corrêa, T., Ferraz, L., \& Lapa, M., (2020): Coalition COVID-19 Brazil II Investigators. (2020). Azithromycin in addition to standard of care versus standard of care alone in the treatment of patients admitted to the hospital with severe COVID-19 in Brazil: a randomised clinical trial. The Lancet, 396(10256), 959-967.

- Godleski, M., \& Umraw, N., (2020): Rehabilitation Management During the Acute Phase. In Handbook of Burns Volume 1 (pp. 385392). Springer, Cham.

- Gupta, M., \& Kumar, U. (2018): Treatment of Superficial big Burn Wound by Haridra MalaharaA Single Case Report. International Journal of Ayush Case Reports, 2(3), 27-31.

- Joo, S., Lee, S., Cho, Y., Lee, K., \& Seo, C., (2020): Effects of Robot-Assisted Gait Training in Patients with Burn Injury on Lower Extremity: A Single Blind, Randomized Controlled Trial. Journal of Clinical Medicine, 9(9), 2813.

- Keogh, J., Cox, A., Anderson, S., Liew, B., Olsen, A., Schram, B., \& Furness, J. (2019): Reliability and validity of clinically accessible smartphone applications to measure joint range of motion: A systematic review. PloS one, 14(5), e0215806.

- Lee, S., An, S., Kim, N., Kim, U., \& Kim, J., (2016): Reconstruction of post burn contracture of the forefoot using the anterolateral thigh flap. Clinics in orthopedic surgery, 8(4), 444-451.

- Luca-Pozner, V., Delgove, A., Kerfant, N., Karra, A., Herlin, C., \& Chaput, B. (2020): Medial sural artery perforator flap for leg and knee coverage: extended skin paddle with 2 perforators. Annals of plastic surgery, 85(6), 650655.

- Mason, S., Nathens, A., Byrne, J., Gonzalez, A., Fowler, R., Karanicolas, P., \& Jeschke, M., (2017): Trends in the epidemiology of major burn injury among hospitalized patients: A populationbased analysis. The journal of trauma and acute care surgery, 83(5), 867.

- Norkin C, \& White D,. (1958): Measurement of Joint Motion A Guide to Goniometry. Philadelphia: FA Davis; 1985.
- Özkal, Ö., Topuz, S., Karahan, S., Erdem, M., Konan, A., \& Yastı, A., (2020): Clinical predictors of pulmonary functions, respiratory/peripheral muscle strength and exercise capacity at discharge in adults with burn injury. Disability and rehabilitation, Journal of Burn Care \& Research, 39(6), 881-886.

- Ramirez-Blanco, C., Ramirez-Rivero, C., DiazMartinez, L., \& Sosa-Avila, L., (2017): Infection in burn patients in a referral center in Colombia. Burns, 43(3), 642-653.

- Rivas, E., Tran, J., Gutierrez, I., Chapa, M., Herndon, D., \& Suman, O., (2018): Rehabilitation exercise increases physical activity levels in severely burned children while improving aerobic exercise capacity and strength. Journal of Burn Care \& Research, 39(6), 881-886.

- Schneider J., Holavanahalli R., Helm P., Goldstein R., \& Kowalske K., (2006): Contractures in burn injury: defining the problem. J Burn Care, Vol. (27), No. (4), P.p 508-514.

- Schouten, H., Nieuwenhuis, M., van Baar, M., van der Schans, C., Niemeijer, A., \& van Zuijlen, P., (2019). The prevalence and development of burn scar contractures: A prospective multicenter cohort study. Burns, 45(4), 783-790.

- Serghiou, M., Ott, S., Cowan, A., KempOffenberg, J., \& Suman, O., (2018): Burn Rehabilitation Along the Continuum of Care. In Total Burn Care (pp. 476-508). Elsevier.

- Snowdon, D., Leggat, S., Harding, K., Boyd, J., Scroggie, G., \& Taylor, N., (2018): The association between effectiveness of clinical supervision of allied health professionals and improvement in-patient function in an inpatient rehabilitation setting. Disability and rehabilitation, P.P. 1 -10. 31.

- Tan, J., Chen, J., Zhou, J., Song, H., Deng, H., Ao, M., \& Wu, J. (2019): Joint contractures in severe burn patients with early rehabilitation intervention in one of the largest burn intensive care unit in China: a descriptive analysis. Burns \& trauma, 7(1), s41038-019.

- Villafañe, J., Bishop, M., Pedersini, P., \& Berjano, P., (2019): Physical activity and osteoarthritis: update and perspectives. Pain Medicine, Volume 20, Issue 8, August 2019, Pages 1461-1463).

- Vos T, Allen C, Arora M, Barber RM, Bhutta ZA, Brown A, (2016): "Global, regional, and national incidence, prevalence, and years lived with disability for 310 diseases and injuries: a systematic analysis for the Global Burden of 
Disease Study 2015". Lancet. 388 (10053): 15451602

- Vu, K., \& Kowalske, K. (2020): Botulinum Toxin A for improving lack of ankle dorsiflexion range of motion after major burns-a retrospective chart review. Archives of physical medicine and rehabilitation, 101(1), S50-S54.

- Wagner L., \& Clevenger C., (2015): Contractures in nursing home resident, jamda,11(2):94:9. 32.

- Wohlsein, P., Peters, M., Schulze, C., \& Baumgärtner, W. (2016): Thermal injuries in veterinary forensic pathology. Veterinary pathology, 53(5), 1001-1017.

- Zhou, J., Tan, J., Gong, Y., Li, N., \& Luo, G. (2019): Candidemia in major burn patients and its possible risk factors: A 6-year period retrospective study at a burn ICU. Burns, 45(5), 1164-1171. 